\title{
Survey on economic considerations and decisions of key geodata providers and users in Czech public administration
}

\section{Tomáš Řezník ${ }^{1,2}$, Karel Charvát ${ }^{2}$, Lukáš Herman ${ }^{1, *}$, Milan Konečný1}

\author{
${ }^{1}$ Masaryk University, Faculty of Science, Department of Geography, Czechia \\ 2 Czech Centre for Science and Society, Czechia \\ * Corresponding author: herman.lu@mail.muni.cz
}

\begin{abstract}
This paper presents the results of an empirical economic data-based survey of the costs and revenues of geographical data and Web services across public administration in Czechia. The survey was composed of questionnaires and interviews. The data was collected from the 19 biggest public producers of geographical information and 25 organizations that use geographical information. The results focus on the economic consequences of data opening, splitting finances within public administration bodies, the prioritization of activities related to geographical information, licensing issues and life cycle planning etc. We also consider user opinions on the restrictions on the (re)use of geographical information of public administration, including open data.
\end{abstract}

\section{KEYWORDS}

economic survey; finances allocation; geospatial life cycle; spatial data infrastructure; open data

Received: 16 December 2020

Accepted: 29 June 2021

Published online: 25 August 2021

Řezník, T., Charvát, K., Herman, L., Konečný, M. (2021): Survey on economic considerations and decisions of key geodata providers and users in Czech public administration. AUC Geographica 56(2), 182-194 https://doi.org/10.14712/23361980.2021.12

(C) 2021 The Authors. This is an open-access article distributed under the terms of the Creative Commons Attribution License (http://creativecommons.org/licenses/by/4.0). 


\section{Introduction}

It is obvious that geographic data have become an invaluable commodity and play a major role in all aspects of society (Klinkenberg 2003). It is, therefore, logical to address the issue of the economic value of geographical information in the scope of geoinformatics/geographic information science (Krek and Frank 2000; Goodchild 2003; National Research Council 2004; Crompvoets et al. 2010; Hošková-Mayerová et al. 2013; Crompvoets and Broucker 2015; Johnson et al. 2017; Pashova and Bandrova 2017; Coumans 2018; Lü et al. 2019; Craglia and Pogorzelska 2020).

To sum up, value of geographic information is a commonly addressed topic within as well as beyond the geographic community. The research is designed through questionnaires, commonly at a moderated workshop or similar events (ANZLIC 2010a, 2010b). A challenge remains in providing a more complete picture based on empirical economic data together with findings from questionnaires and discussions. Empirical economic data are scarce due to the following reasons. As the first, investments and revenues to geographic information are not explicitly separated from other kinds of data. As the second, investments and revenues to geographic information may differ significantly in time. A longer time extent than one year is required to see a picture without distortions due to a specific year. As the third, it seems difficult to obtain a comprehensive view based on empirical economic data from providers, distributors or users of geographic information.

The overall objective of this paper was therefore to provide a comprehensive economically-based picture of geographic information management in the Czech public administration. The study was conducted in 2016 while taking into account empirical economic data within a time frame between 2011 and 2015 . Processing of all the inputs was performed in 2016. However, the results of the study were only de-classified in 2020 as they contain sensitive economic data. This paper, therefore, brings reflection of research performed between 2016 and 2020 and discusses the changes between the results obtained within our study. Nevertheless, the obtained results seem unique across the world even after five years as no similar study with five-years empirical economic data on geographic information was not performed till then.

Situation in Czechia in 2016 was analyzed from two sides: (1) from the producer's point of view and (2) the user's point of view. The authors of this paper conducted a survey on economic considerations and decisions of key data providers within the Czech public administration. The main motivation was to collect data on costs and revenues from 19 of the most important producers of geographical information within the Czech public administration, as well as from the 25 biggest users of geographical information (both commercial and public administration). Information on the 'playground' (i.e. the available budget) were also taken into account.

Our questionnaire survey was conceived as exploratory research, no precise hypotheses have been established in advance. Due to the main goal and general approach described above, following research question (RQ) were defined:

1. The producer's point of view: "What (economic) decision(s) influenced the process of creating, maintaining and providing geographic data?"

2. The user's point of view: "What geographic data, with respect to their license, do their main consumers prefer and really use?"

3. Information on the 'playground': "What was the size of the market with geodata created within the public administration, i.e. the available budget?"

This paper is structured as follows to address the above-mentioned research questions:

- Section 2 analyses the state-of-the-art in research of economic aspects of geographic information.

- Section 3 deals with methodology, with an emphasis on questionnaires and their application.

- Section 4 presents results obtained from conducted surveys focused on answering given research questions.

- Section 5 discusses the outcomes of the presented research with an emphasis on comparisons with the situation abroad, and in the context of international activities.

- Section 6 summarizes ongoing work with respect to the main achievements.

In the presented paper, we use the term 'geographic data' as data iselves, that are only a set symbols that represent measurements of phenomena, including location (DiBiase 2021). Geographic data can be treated as a commodity in the limited sense of acquisition or sale (Dasgupta 2013). On the other hand, we use the term 'geographic information' as geographic data and services related to them. In general, information is data that has been selected or created in response to a question (Di Biase 2021) and it is a problem to determine the monetary value of the geographic information (Dasgupta 2013).

\section{Related work}

There are several studies with various approaches to assessing the economic value of geographical data. For example, Castelein (2010) measures the economic value of geographical data in the Netherlands in terms of employment, turnover, activities, and themarket. OXERA (1999) describes the approach to estimating the economic contribution of Ordnance Survey (OS) in Great Britain. They found that OS contributed $2-20 \%$ gross value added in relevant sectors of the national economy (utilities, local government and transport). Genovese et al. (2010) used the value chain concept to assess the value of geographical information in Quebec, Canada. 
The cost-benefit analysis (CBA) is a common method related to the economic value of geographical data, especially in the case of forecasting (Pick 2005; Obermeyer 2008). CBA is employed in a countless number of domains, programmes, projects and applications. In the domain of geographical information, CBA is usually used for estimating future costs and potential benefits (e.g. Gillespie 2000). Frank (2001) applied CBA on topographic surveying in Austria and found that topographic data contributed $€ 100$ Mil. to private sector activities. The methodology used to calculate benefits is based on OXERA's (1999) gross value-added approach. Similarly, Halsing et al. (2004) performed CBA of the National Map, produced by the U.S. Geological Survey (USGS). Halsing et al. (2004) also developed a simulation model "NB-Sim" to estimate the number of application implementations occurring each year to calculate the value. The net present value of a fully implemented version of the National Map is over $\$ 2$ billion. Cetl et al. (2008) applied CBA on future improvements of the entire NSDI (National Spatial Data Infrastructure) in Croatia.

However, empirical statistics regarding the value of geographical information, both in terms of the cost and benefit, are often missing. Without empirical economic data, the geographical community tends to provide descriptive cost-benefit considerations as for example in Toth and Smits (2009). It is then difficult to convince members of other communities, including politicians and policy makers, of the importance of geographical information. Some studies using real economic numbers are rare; some of these include e.g. ANZLIC (2010a, 2010b), DEWBERRY (2011) and Craglia et al. (2012).

ANZLIC (2010a, 2010b) describes CBA conducted in respect of fundamental data (topographic maps and orthophoto) in Australia. In this case, CBA constituted the second stage of the assessment addressing the effects of four variants of pricing models. The following sources were used as input data for the quantitative part of the analysis: materials by government agencies, previous estimates in the literature, and annual reports of agencies. Specifically, the economic aspects of four fundamental data sets were analysed: Western Australia topographic data, Western Australia aerial photography, Victorian topographic data and Geoscience Australia topographic data $(1: 250,000)$. The total cost of these datasets ranges from $\$ 2,873,000$ (Western Australia topographic data) to $\$ 13,292,000$ (Geoscience Australia topographic data), while production and maintenance costs of these datasets range from 88.5 to $99.9 \%$ of the total costs (ANZLIC 2010b).

The CBA provided in DEWBERRY (2011) report on USGS National Enhanced Elevation Assessment included both tangible and intangible benefits. This report defined business uses in 34 federal agencies, as well as in other private and non-profit organisations. Data were collected through online questionnaires, interviews and workshops with key managers and elevation data users. The assessment results provide significant evidence that an enhanced elevation program in the US could provide estimated net benefits between \$ 116 Mil. and \$ 620 Mil. per year.

Craglia et al. (2012) addressed the economic aspects of geographical data in the context of Environmental Impact Assessments (EIAs), Strategic Environmental Assessments (SEAs) and INfrastructure for SPatial InfoRmation in Europe (INSPIRE) Directive (Directive 2007/2/ES). This study analysed the results of online survey, which was conducted in 2009 across the European Union (EU) and included 128 respondents from 21 countries. Results showed that problems persist and additional costs due to data access problems were at least $€ 150$ Mil. Based on the conducted survey, Craglia et al. (2012) assumed that the annual average number of EIAs and SEAs in the EU27 far exceeded the estimated 24,000, implying that there should be savings far greater than $€ 150$ Mil. per year.

More recently, national mapping organisations from 11 European countries realised a EuroSDR project to explore the economic value of 3D geographic information in 2017. For the investigated cases, the cost-benefit ratio of 3D to 2D geographic information was found to be about 3:1, but the calculated financial benefits were rather circumstantial (Coumans, 2018). Deloitte (2018) investigated socio-economic impacts of Open European Location Services (ELS). They identified positive impacts of open ELS on geo-spatial information market data-economy, in general. These conclusions are based on 21 questionnaire replies (10 of them from Spain) and they are not substantiated by any empirical numbers.

In summary, economic analyses of geographical information seem to share the following features:

1. Empirical economic numbers are missing in the majority of analysed sources. In several cases, the CBA method attempts to forecast the future, i.e. empirical economic numbers are not applicable. The related studies mostly conclude with lists describing the benefits and challenges and/or general recommendations.

2. The geographical information community seems to have had the greatest interest in the cost-benefit consideration at the beginning of the new millennium. Publications after 2012 appear to be rather scarce.

3. The majority of relevant studies take into account only a single product, most typically topographic maps or orthophoto. A comprehensive perspective cutting across various topics is not available.

\section{Methodology}

The primary aim of the presented research was to find consistent answers to particular research questions 
related to value of geographical information across public administration in one country. In total, 31 bodies ${ }^{1}$ of public administration within the Czechia were chosen since they represented the most important producers, re-producers and users of geographical information. The commercial subjects were a part of the discussions on value of geographical information, however, not a direct participants of the conducted survey.

Our surveys aimed at several aspects more or less tightly connected to economic value of geographical information. The primary interest was to discover what is the structure of a budget allocated to geographical information; both externally and internally. The external point of view dealt with the way how finances are allocated between an organisation - to geographical information and beyond as well in fiscal year. The internal point of view discovered the structure of allocated finances: to data production, data maintenance, Web services development and maintenances, revenues for selling the geographical data/ services. The last primary interest aimed at identification of barriers on geographical data/services use from a confrontation of user's and producer's perspectives. Among others, the authors are aware that many of the questions raised are not purely economic ones as they are also closely related to policy and political decisions.

Two questionnaires were devised during April 2016 through collaboration between the authors' team, three related research projects running in parallel, and the Czech Ministry of Interior. Questionnaires were made in line with the consensus reached between the Czech Ministry of Interior, Czech Technological Agency (as a financing body of the project) and principal investigators of the project. It was also emphasised that questionnaires should not remain the only method for data (re-)producers as it has to be accompanied with iterative in-depth discussions.

The structure of the questionnaires originated from: (1) requirements of the Czech Ministry of Interior, (2) feedback with representatives from the European Commission, Directorate General Joint Research Centre, to become at least partially compliant to the survey of Craglia et al. (2014), (3) life-cycle of geographic information as defined by the Stages of the Geospatial Data Lifecycle (FGDC 2010). Both questionnaires are presented in the Appendixes.

The rationales of the two questionnaires were as follows:

The questionnaire for geographical information producers (Appendix 1, available at https:// doi.org/10.14712/23361980.2021.12), comprising 25 questions, was sent to 31 bodies of Czech public administration who were the biggest producers and re-producers of geographical information. The

1 The groups of 19 key data providers and 25 biggest users of geographical information partly overlaps. questionnaire was pre-completed by a (re-)producer and later on completed during personal interviews with respondents at their premises in order to increase the veracity of the collected answers. Financial information was requested by the Czech Ministry of Interior for years 2011-2015. Moreover, written and collectively finalised answers were compared with other sources of information, e.g. metadata from the national geoportal or information available from INSPIRE monitoring and reporting (European Commission 2017). In total, 19 bodies of public administration, i.e. $61 \%$, participated, while 12 bodies, i.e. $39 \%$, did not provide any feedback. All the (re-)producers were invited for two workshops (see below) to further discuss, update and/or clarify their positions.

The questionnaire for users of geographical information (Appendix 2, available at https://doi.org /10.14712/23361980.2021.12), comprising 14 questions, was intended to ascertain the users' points of view regarding geographical information. This second questionnaire was presented to 60 organisations, mostly commercial and research companies. In total, 25 completed questionnaires were returned, equating to $42 \%$ of the organisations approached. Though this may see a low figure at first glance, the respondents comprised the biggest commercial companies, as well as the Czech Armed Forces. The questionnaire for users of geographical information was, in contrast to the first questionnaire, not verified by personal interview nor against other sources of information to reach as broad an audience as possible.

Two one day workshops were organised by the Czech Ministry of Interior to further process and clarify the obtained results as well as the whole economic-based picture. These workshops were used for a confrontation of user's and producer's perspectives as both groups were invited and discussed together. Workshops as another method of investigation were applied similarly to ANZLIC (2010a, 2010b).

Both questionnaires were answered between 1 May 2016 and 30 September 2016. All respondents had the opportunity to revise their previous answer(s) up to the end of the survey. The project had the support of the Czech Ministry of Interior, which allowed the collection of detailed answers including figures concerning both civil and military budgets. Both questionnaires were developed as structured ones; however, free text additions to any question were also collected in order to obtain information that was as detailed as possible.

The economic values from questionnaires were analyzed using methods of descriptive statistics. Simple statistical measures were used including means, medians, standard deviation, range and interquartile range for five years time extent for each (re-)producer of geographic information. Aggregated form was also provided for: (1) all the (re-)producers of geographic information, (2) for civil and military national mapping organisations and (3) all the (re-)producers 
of geographic information except for civil and military national mapping organisations. Results were expressed through common types of graphs, from pie charts to box-plots.

Results of the questionnaire for geographical information producers were, where possible, also compared with results obtained during INSPIRE Public Consultations between December 2013 and February 2014 (Craglia et al. 2014) in order to compare the national status with the European/international one. The European insight comes from 698 completed replies from more than 30 countries, including 27 within the EU, 3 in the European Economic Area, 4 other European countries and 2 replies from US/ Canada. As the last, the information discovered within this study was also compared to the world-wide similar research conducted between 2016 and 2020.

\section{Results and interpretations}

\subsection{Available budget between 2011 and 2015}

The information on year-to-year budget available within the five years preceding the survey was understood as ground information. The average annual budget provided information on the 'size of the playground' for geographical information (re)production within public administration. The five-years perspective demonstrates the stability of funding available for geographical information over time.

The available budget for geographical information between 2011 and 2015 in 19 bodies of public administration in Czechia equalled $€ 1.2$ billion. The financial support was stable and increasing in time, with annual support between $€ 210$ and $€ 270$ Mil., while the average annual value was $€ 239$ Mil.

Detailed empirical economic data were not available after 2016 to provide a credible basis for more up-to-date information, including trend analysis in longer term. The outcomes of the 2016 study are considered by the Ministry of Interior as crucial still in 2021. The Czech (national) Strategy of Geographical Information Infrastructure is being revised in 2021 to, among others, reflect the results of the study presented within this paper (Kubátová 2017).

\subsection{The data (re)producer point of view}

The first set of questions in the questionnaire for geographic information (re-)producers concerned geographical data and services discoverability and availability, since they represent a bridge between geographical information (re-)producers and users. It has been proved that the discoverability of geographical information increased significantly within 2011-2015 as a result of requirements set for metadata and discovery services, as defined in the EU INSPIRE Directive (Directive 2007/2/ES and Řezník
2013). The majority of metadata, i.e. $44 \%$, were available in INSPIRE-structured XML format. This figure may appear low since the European survey in 2014 found that about $58 \%$ of metadata was according to the INSPIRE requirements (40\% INSPIRE compliant, $18 \%$ partially INSPIRE compliant). Note, however, that this research was aimed at all geographical data within public administration and not only at public administration bodies managing geographical information under INSPIRE. On the other hand, according to the free text answers obtained and verification at the INSPIRE national geoportal, such metadata have little or no information on data quality. Since 2019, all the geographic data and services published under the INSPIRE directive have been described by $100 \%$ with metadata (INSPIRE Knowledge Base 2021). Further information on the discoverability of geographical data and services may be found at Rezník et al. (2016).

The second question dealt with opening of geographical data. As depicted in Figure 1, in Czechia, $89 \%$ of geographical information (re)produced at the public administration level is available on the Web. As in many other countries, the phenomenon of the 'shapefile' was the dominant vehicle for encoding. Modern methods of interoperable encoding, like GML (Geography Markup Language) and/or (Geo)JSON (JavaScript Object Notation), were used in $11 \%$ of all publications. Nevertheless, semantic approaches like that described by Berners-Lee (2006), e.g. linked RDF (Resource Description Framework), were not used in 2016 among the surveyed bodies of public administration as they remained activities for research and pilot applications; that is, they were not massively used. More up-to-date numbers since 2016 are not available as they are not a part of INSPIRE monitoring $\&$ reporting or any other similar activity.

Figure 2 offers an alternative perspective on geographical data flows, which is also comparable to results on the European level (Craglia et al. 2012; Cetl et al. 2017). We can clearly see that the INSPIRE Annex I spatial data themes (Coordinate reference systems, Geographical grid systems, Geographical names, Administrative units, Addresses, Cadastral

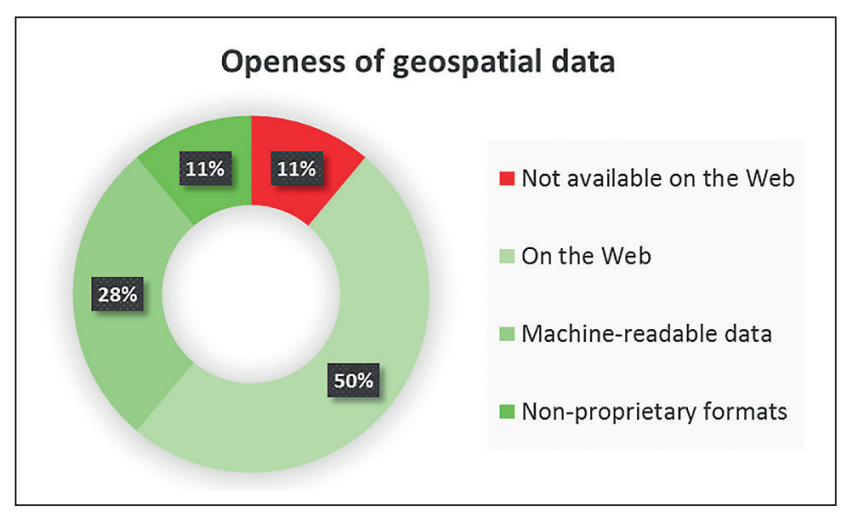

Fig. 1 Openness of geographical data within Czech public administration according to the five star rating of Linked Open Data. 


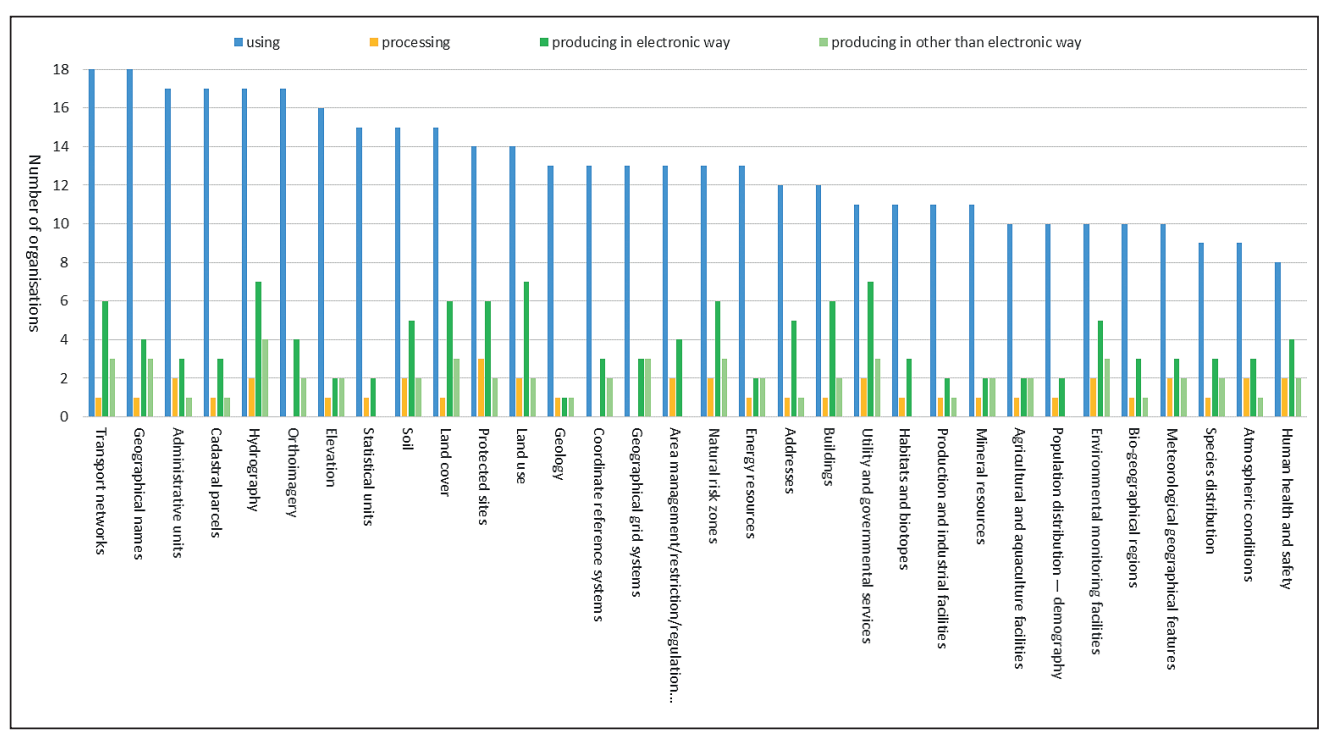

Fig. 2 Number of organisations of Czech public administration using, producing or reproducing different INSPIRE themes.

parcels, Transport networks, Hydrography and Protected Sites) were the most commonly used, as they represent reference data. Surprisingly, reference data for identical themes were typically duplicated among several organisations. It was also discovered that the duplication of data and services within one ministry has been eliminated with the adoption of INSPIRE while cross-ministerial duplication has remained. In contrast, thematic data (from INSPIRE Annex III) were the most commonly used forms for reproduction. In other words, added value in the sphere of reproduction was higher for thematic spatial data than for reference data.

Answers to financial questions provided the following findings. $66 \%$ of respondents did not have a key for splitting finances between 2011 and 2016 within their organisation, e.g. to department level. As a result, ad hoc financing took place. Data were then updated according to available finances, without reference to their life cycle (when following the definition of the life cycle as declared in Stages of the Geospatial Data Lifecycle (FGDC 2010). The same number of respondents $(67 \%)$ answered that they did not have a list of priorities when investing into geographical data and services. A subsequent question was related to the existence of a life cycle for geographical information. $72 \%$ of respondents had not developed a life cycle information plan. As a consequence, finances were typically invested during the second half of a year into the most visible showcase, i.e. a geoportal. The opposite situation, homogeneous financial planning, existed in civil and military national mapping organisations, some regional governments, the Czech Geological Survey, and the Nature Conservation Agency of the Czech Republic (33\% of respondents).

Figure 3 depicts the percentages of bodies that offer the respective proportions of their geographical data and services free of charge. Almost one half of the organisations surveyed offered all their geographical data and services free of charge. This situation applied mostly to small and medium geographical data producers, where (according to their statements) administrative costs related to the collection of fees would be higher than the expected income. Almost two thirds of respondents answered that their geographical data and services could be ordered via an e-shop.

Further information to Figure 3 is the following. Three research organisations kept between 2011 and 2015 some of their geographical datasets private; i.e. they did not disseminate any information, even on a paid basis. As understood from free text comments and mutual clarifications, their geographical datasets were so attractive that the desire to have access to them might be a reason for joining newly emerging (research) project consortia.

Figure 4 offers a unified view of the splitting of finances in the geographical domain within the public administration of one country. In total, this referred to a budget of approximately $€ 239$ Mil. per year for 19 bodies of public administration that

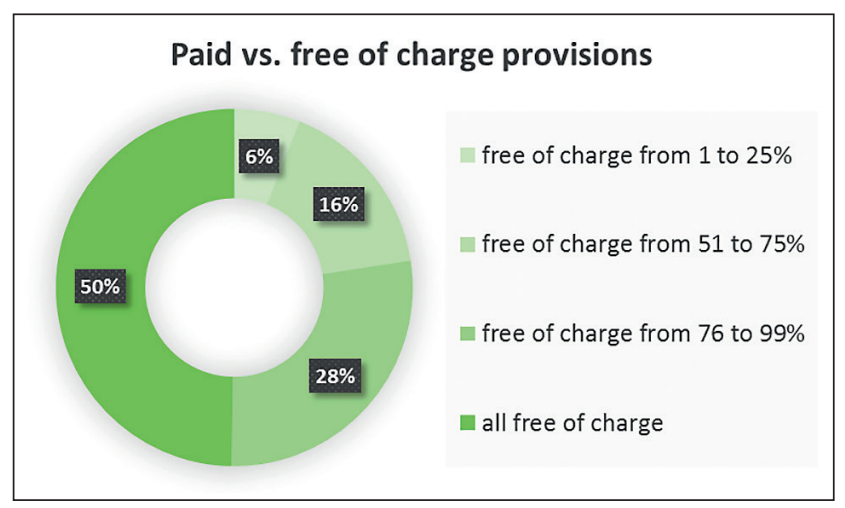

Fig. 3 Responses to the question of what proportion of geographical data and services are provided free of charge by the organisation. 


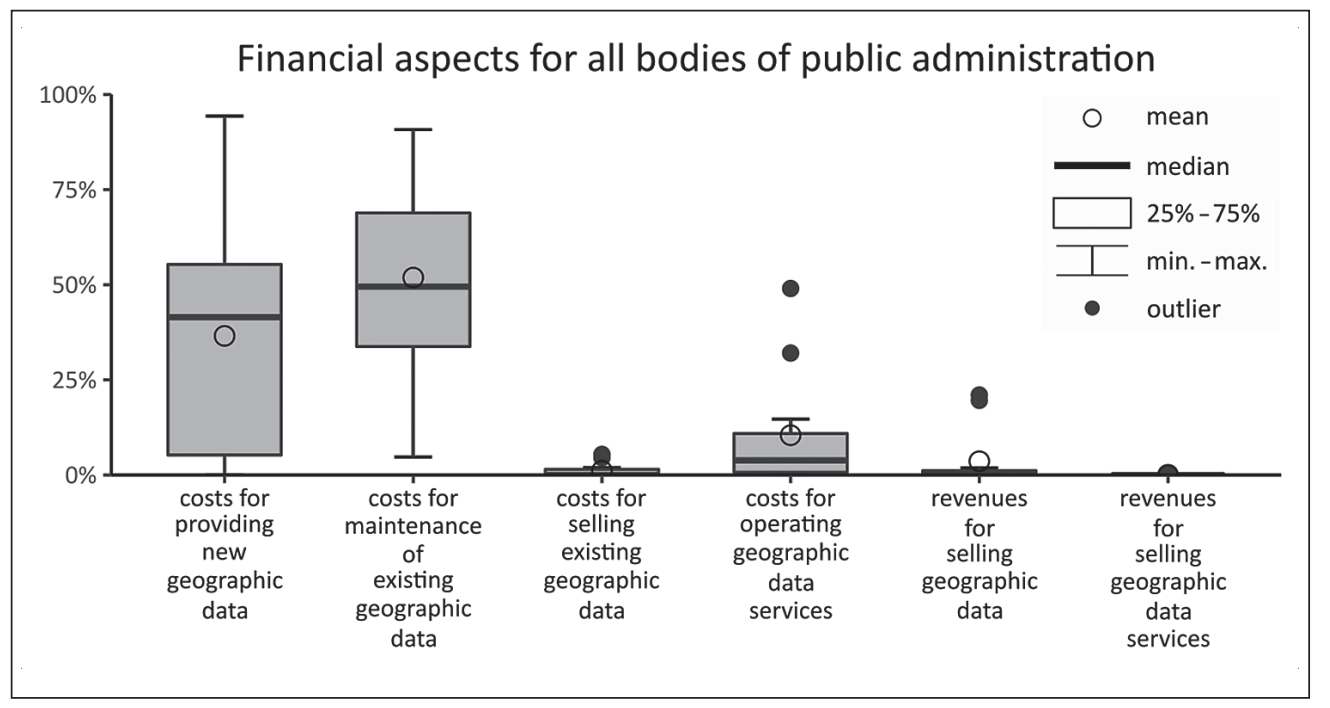

Fig. 4 Descriptive statistics of financial aspects expressed as a ratio of direct costs or revenues and the total organisation's budget in a form of a box-plot; data from the whole of public administration.

are, at the same time, key producers of geographical information.

It is evident from Figure 4 that average costs between 2011 and 2015 varied to a huge extent, especially when talking about the costs of providing new geographical data and the costs of maintaining geographical data. The cost of providing new geographical data varied between 0 and $94 \%$ of the total budget allocated to geographical information.

When following Figure 4, directly received revenues account, on average, for only $4 \%$ of the overall investment into geographical information. Such a number comprises all the costs concerning provision/ maintenance/selling of geographic data and operating geographic data services on the one hand and revenues for selling geographic data and services on the other hand.
Only one correlation was found between bodies of public administration when talking about costs and revenues for geographical information, see Figure 5. Czech civil and military national mapping organisations evince similarities in budget spending despite having different structures, end user groups, and total budgets ( $€ 36$ Mil. per year vs. $€ 2.6$ Mil. per year). Figure 5 shows that civil and military national mapping organisations typically spent their yearly budgets as follows:

- $5 \%$ on providing new geographical data,

- $90 \%$ on the maintenance of existing geographical data,

- $2.5 \%$ on the sale of existing geographical data (e-shop developments, administrators, lawyers, key accountants etc.),

- $2.5 \%$ on operating spatial data services.

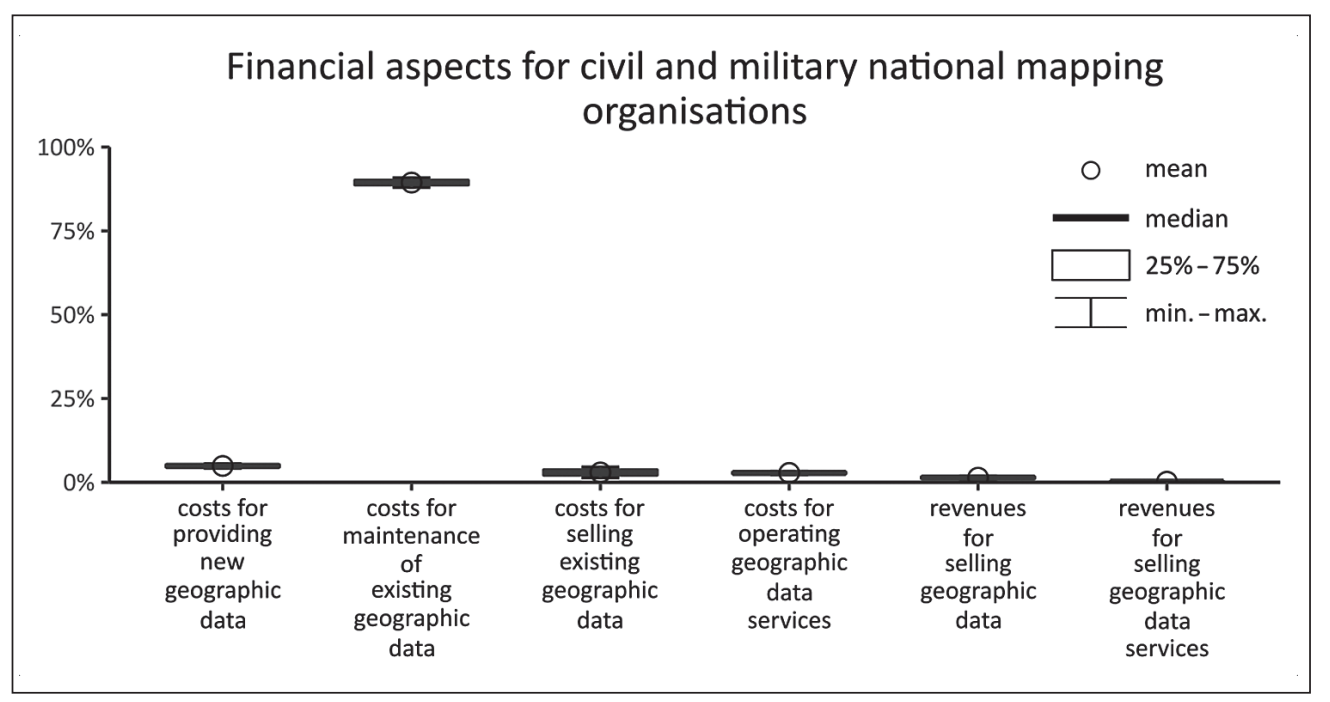

Fig. 5 Descriptive statistics of financial aspects expressed as a ratio of direct costs or revenues and the total organisatin's budget in a form of a box-plot; data from Czech civil and military national mapping organisations. 
However, for the whole of public administration in general, revenues for selling geographical data reached $2 \%$ and revenues for selling geographical data services reached $0.5 \%$ of the total budget. It may be concluded that geographical data services did not have direct profitability according the conducted survey, since revenues for selling geographical services only cover $15 \%$ of the costs of operating such geographical services. However, the majority of the offered geographical services were (and as far as authors are aware still are) provided free of charge to public administration bodies and/or citizens. Such 'zero payments', so-called 'virtual payments', are not included in Figure 4 and Figure 5. For instance, 'zero payments' only from the Czech public administration to the Czech civil national mapping organisation (the Czech Office for Surveying, Mapping and Cadastre) reached $24 \%$ of their total annual budget.

Even when we filtered out civil and military national mapping organisations, the picture is still the same, as may be seen when comparing Figure 4 and Figure 6 . There was no correlation between bodies of public administration from the budget analysis point of view, no matter what their level (national, regional, local), size (overall budget, number of employees) or type (administrative bodies, research institutes). It may therefore be concluded that such a situation was, among others, also a consequence of the absence of mid- and long- term planning. As mentioned above, the absence of a life cycle plan was reported by three-quarters of respondents. Finances were allocated ad hoc without appropriate planning. As a result, one body of public administration might spend $94 \%$ of its yearly budget on providing new geographical data while another might spend $65 \%$ of its yearly budget on the maintenance of existing geographical data.

Direct revenues for selling geographical data and services reached up to $10 \%$ of the costs of their provision, operation and maintenance. The costs of selling existing geographical data, among others lawyer and key accountant services, were, on average, equal to $150 \%$ of the revenues received from sales of geographical data. However, geographical data of public administration were commonly shared and/ or traded for other commodities, as in the case of the mapping department of the Czech Armed Forces. Note that data for indirect revenues were available only for civil and national mapping organisations. Another added value of geographical information lies in the area of decision making. Geographical information is one of the most commonly used references on which a decision is made.Such indirect profitability cannot be explicitly evaluated through economic figures.

Another question posed to bodies of Czech public administration was dedicated to their opinion on Public-Private-Partnership (PPP). As depicted in Figure 7, $42 \%$ of respondents supported the idea of PPP in order to decrease the financial burden related to geographical information, while the same number were against. The remaining $16 \%$ failed to provide an answer to the question. When going into depth, PPP sceptics believed that the existing financial model for geographical information in public administration was a simple and stable one, despite its midand long-term rigidity and disunity. Such negatives were mentioned especially when talking about huge investments.

\subsection{User point of view}

The beginning of the second questionnaire was devoted to the usage of open geographical data and/ or services from public administration. It was found that $79 \%$ of respondents use open geographical data and/or services offered by Czech public administration. Out of that $79 \%$, the following proportions of

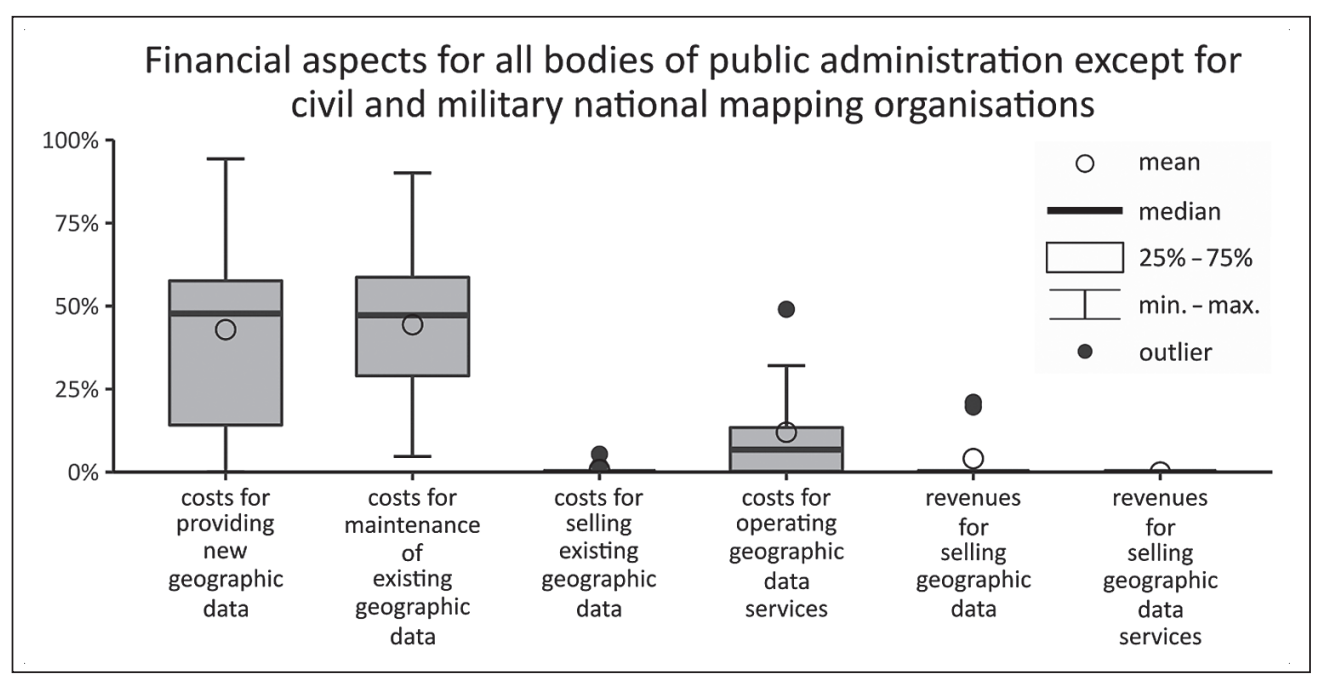

Fig. 6 Descriptive statistics of financial aspects expressed as a ratio of direct costs or revenues and the total organisation's budget in a form of a box-plot; data from the whole of public administration except for Czech civil and military national mapping organisations. 


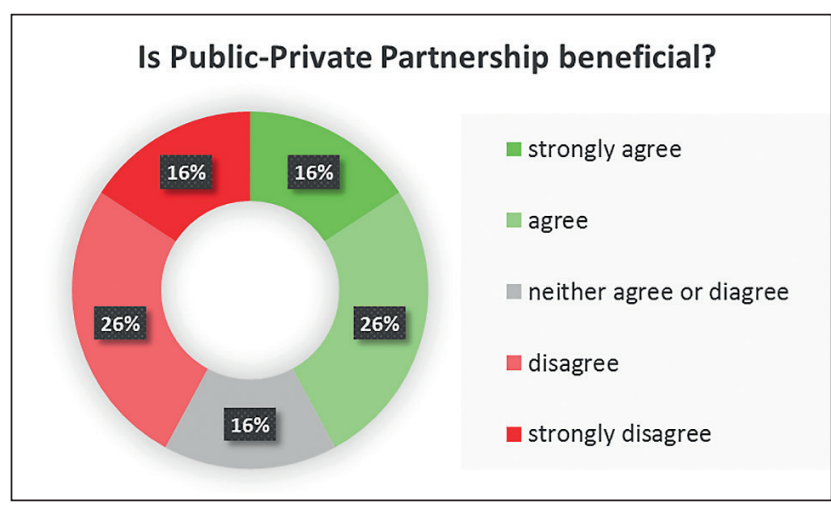

Fig. 7 Responses to the question of whether organisations are convinced that it would be beneficial for them to cooperate through a Public-Private Partnership (PPP) in order to publish their geographical data and/or services.

respondents used geographical data/services from the respective institutions and databases:

- $80 \%$ used the national Registry of territorial identification, addresses and real estate (in Czech Registr územní identifikace, adres a nemovitostí, abbreviated as RÚIAN),

- $60 \%$ used the Cadastre of Real Estate,

- $50 \%$ used orthoimagery of the Czech national mapping organisation,

- $30 \%$ used the national hydrographic database DIBAVOD (Digital Database of Water Management Data, in Czech DIgitální BÁze VOdohospodářských Dat),

- 25\% used the Farmer's portal of the Czech Ministry of Agriculture,

- $25 \%$ used the data/services provided by Prague Institute of Planning and Development.

The majority of the most commonly used geographical data and services were open ones. It is clear from the answers that open geographical data and services were used:

- for internal purposes in $84 \%$ of cases,

- in $68 \%$ of cases involving contracts for the public sector,

- in $52 \%$ of cases involving contracts for the private sector.

While open geographical data and/or services were used by $79 \%$ of responders, paid geographical data and/or services were used by $65 \%$ of respondents. Indeed, when the detailed answers were analysed, we saw that paid geographical data and/or services were used:

- for internal purposes in $71 \%$ of cases,

- in $65 \%$ of cases involving contracts for the public sector,

- in 35\% of cases involving contracts for the private sector.

In other words, geographical data and/or services of public administration were available for contracts with the public sector no matter whether they were used on a paid basis or free-of-charge. A very common mechanism in such types of contracts was that a commercial company asks via one body of public administration for geographical data/services provided by another body of public administration. The obtained geographical data/services were then available free of charge to the commercial company as a subcontractor of the body of public administration providing the data. That is, the fees are not counted.

The biggest difference existed in contracts for the private sector. In such cases, the majority of users (54\%) used open geographical data/services rather than products offered by public administration on a paid basis. Compared to $35 \%$ of users buying geographical data/services from public administration bodies, only $11 \%$ of users bought geographical data/ services from a commercial company.

OpenStreetMap was the most important example when talking about the open substitution of paid geographical data/services of public administration. OpenStreetMap was used in $90 \%$ of all cases in which open geographical data/services were used instead of those offered by public administration on a paid basis. Czech users would prefer to use the Fundamental Base of Geographic Data of the Czech Republic (abbreviated in Czech as ZABAGED); the key topographic map in scale $1: 10,000$. However, they were discouraged by its price of about $€ 13,800$ for planimetric components and $€ 3,900$ for altimetry for the area of the Czechia, i.e. $78,870 \mathrm{~km}^{2}$. In total, $91 \%$ of respondents would rather use the national geographical data/services of public administration if they were free of charge. The most requested were the following geographical data/services:

- The Fundamental Base of Geographic Data of the Czech Republic (ZABAGED) - 70\% of respondents;

- National products of laser scanning, the Digital Terrain Model of the Czech Republic in its fourth (DMR 4G) and fifth (DMR 5G) generations, and the Digital Surface Model of the Czech Republic in its first generation (DMP 1G) - 25\% of responders;

- The national military reference dataset (abbreviated in Czech as DMÚ 25), the national dataset on road and railway networks and archived aerial images, as well as cadastral maps $-10 \%$ of responders.

The described situation started to change in the period between 2016 and 2020. The base map of the Czech Republic, abbreviated 'Data50', is published as open data since April 2019. The base map of the Czech Republic corresponding to the scale $1: 200,000$ ('Data200') was opened that time as well. The Czech Statistical Office and the Czech Hydrometeorological Institute have also opened their geographical data between 2016 and 2020. Note cadastral data remain opened since 2012, cadastral maps since 2014.

Figure 8 presents an overview of the five biggest barriers to the (re)use of geographical information as identified in the results of the questionnaire for users of geographical information. As expected, fees were the biggest barrier as recognized by almost half 
of the respondents. The second biggest barrier was that metadata were weak. The quality of metadata, services and data itself has improved due to the coordinated approach taken between 2016 and 2020 as stated by INSPIRE Knowledge Base (2021). As noted with respect to the data (re)producer's point of view above, it remains a question how a user should evaluate the applicability of the discovered data when (s) he has (almost) no information on data quality. The third most important barrier lied in the area of communication between the (re)producer and user. The fact that methods of giving feedback were overcomplicated was highlighted, especially when comparing attempts to provide feedback on public and commercial geographical products; providing feedback on the latter was reported to be much easier.

The existence of license agreements and the fact that standardization efforts were not followed correctly were commonly mentioned as barriers within the geographical community. Surprisingly, the pan-European proposal of instituting unified INSPIRE licences had not helped the situation until 2015. In 2019, efforts have been made within the Coordination Committee to harmonise data in the INSPIRE infrastructure and use Creative Commons licence (CC 4.0). But there are still others whose legislative burdens prevent them from making data available under the CC 4.0 as stated by INSPIRE Knowledge Base (2021).

On the positive side, only less than half of users recognised barriers when using geographical information provided by public administration.

\section{Discussion}

Discussion is firstly structured with respect to the research questions of this paper and secondly with a broad discussion with primary focus on research presented within the years 2016 and 2021.

\subsection{RQ1: "What (economic) decision(s) influenced the process of creating, maintaining and providing geographic data?"}

Creation, maintenance and provision of geographic data seem to be the most influenced by ad hoc allocation of finances. Finances pertaining to geographic information were in the Czechia allocated ad hoc between the years 2011 and 2015, typically within the second half of the given year and used primarily to increase the quality of presentation to a wide audience. As such, finances were rather allocated primarily to extensions, modifications and updates of geoportal instead of investments to the quality of geographic data. Such a situation starkly contrasts with a planbased approach in the United States of America, United Kingdom and Australia (ANZLIC 2010a, 2010b; DEWBERRY 2011; OXERA 1999).

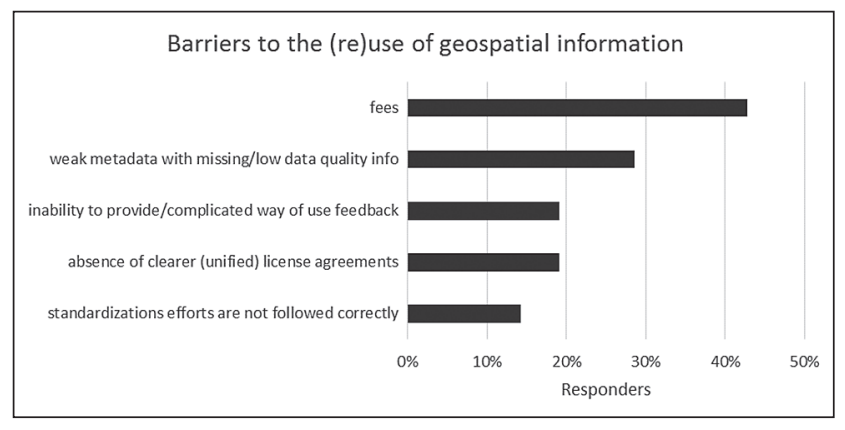

Fig. 8 Barriers to the (re)use of geographical information from public administration from the user's point of view.

It seems that the described trend was changed between 2016 and 2020 mainly due to the following aspects: (1) data of public administration became more commonly opened which appeals to their quality, (2) geoportals evolved to a complex optimised tools. The newly prepared Czech Strategy of Geographical Information Infrastructure (GeoInfoStrategy) after 2021 stresses the quality of geographic data even more than the preceding GeoInfoStrategy for years 2014-2020.

\subsection{RQ2: "What geographic data, with respect to their license, do their main consumers prefer and really use?"}

The results of the conducted study proved that the most commonly used geographic data were identical to the reference data as defined in Annexes I and II of the (European) INSPIRE directive (Directive 2007/2/ ES). Namely in the order according to their use, transport networks, geographical names, administrative units, cadastral parcels, hydrography, orthoimagery, elevations, statistical units, soil, land cover, protected sites and land use belonged to the most commonly used spatial data themes throughout the Czech SDI (Spatial Data Infrastructure). This list of themes seem to remain stable as it was also confirmed by the INSPIRE monitoring and reporting data within the period from 2016 to 2020 .

It was also confirmed in the conducted study that fees were the biggest barrier for the Czech users. Users prefered geographic data, services and maps provided by the Czech public administration; however were discouraged by their price and license restrictions that allow use only within the given time extent (typically up to five years). Such a situation changed within the period from 2016 to 2020 . Several geographic data produced by public administration were opened within the last five years. More detailed examples are provided in section 4.4. Creative Commons licence (CC 4.0) became the most common used license throughout the geographic data published under the INSPIRE directive (INSPIRE Knowledge Base 2021). 


\subsection{RQ3: "What was the size of the market with geographic information created within the public administration, i.e. the available budget?"}

Size of the market with geographic information within public administration is with its size of $€ 239$ Mil. in average between 2011 and 2015 per 10 million inhabitants country comparable to other developed countries (ANZLIC 2010a). The annual support varied in the given period from $€ 210$ to $€ 270$ Mil. The five years time extent window showed a positive trend in finances allocation. The available budget increased for more than $25 \%$ within five years which was more than inflation that was $7.3 \%$ in the given five years period; $1.5 \%$ yearly average respectively (CZSO 2021).

The outcomes of the conducted study in 2016 remain also in the year 2021 the only empirical economic data on geographical information within the public administration of the Czechia. The Ministry of Interior uses the results of our study as a basis for economic considerations concerning the upcoming Czech (national) Strategy of Geographical Information Infrastructure from the year 2021 to 2027 (Kubátová 2017).

Companies from the private sector did not provide any economic inputs, as a priori expected. The full size of the Czech market with geographic information remains hidden.

\subsection{General discussion}

Purely economic considerations lead to a very different perspective compared to that of a scientist or a researcher. Since bodies of public administration are non-profit in the narrow sense of the word, revenues lost by the "opening" of data are considerably less important than the costs of investing in new hardware and software in order to service a significantly greater number of users. Paradoxically, geographical data/ services are in some cases provided on a paid basis as a kind of a budget saving measure. Some believe that engaging in Public-Private Partnerships may present a way of reducing costs when data are published in an open form. However, the benefits of PPP remain questionable since respondents are divided into two polar opposite groups, i.e. strong supporters and strong opponents.

The lack of a life cycle definition seems to be the most important barrier to a more efficient geographical information financing. A plan-based approach like in the United States of America (DEWBERRY 2011), United Kingdom (OXERA 1999) and Australia (ANZLIC 2010a, 2010b), would be more suitable for the (Czech) public administration. Such a plan should be based on an analysis of the requirements with respect to inventorying or evaluating existing geographical information, obtaining new geographical information and accessing, maintaining/archiving and using/evaluating such information. The authors of this paper proposed a methodology for developing a life cycle for geographical information which has been certified by the Czech Ministry of the Interior (as a complementary achievement to the conducted survey). At the same time, advice on establishing a cross-ministerial 'Fund for Key Geographical Information' was given in the form of a recommending report. Finances from the national budget and other resources such as EU project grants should then be assigned to a body of public administration according to the life cycle plan. Such an approach should help in reducing the cross-ministerial duplication of data and services, since intra-ministerial duplication has been eliminated by pan-European harmonisation achieved under the INSPIRE Directive (Directive 2007/2/ES).

The results of the conducted survey were classified between 2016 and 2020. The state-of-the-art analysis was performed in both time frames, in 2016 when the project finished, as well as in 2021 when this paper was revised. No surveys focused on economic aspects of geographic information have been conducted in Czechia since 2016. Relevant studies throughout the world with focus on economic values of geographical information paradoxically seem the same since no new major achievements have appeared since 2016 (Johnson et al. 2017; Pashova and Bandrova 2017; Coumans 2018; Lü et al. 2019; Craglia and Pogorzelska 2020).

\section{Conclusions}

Geographical information from public administration has an irreplaceable role in all kinds of human activities. On the contrary, it was shown that geographical information within Czech public administration did not boast direct profitability between the years 2011 and 2015. In other words, directly received revenues account, on average, for only $4 \%$ of the overall investment into geographical information. In the case of the Czech national mapping organisation, maximum direct revenues reached $21 \%$ of the total budget. The above mentioned numbers, however, provided only a black and white picture. If we want to see a more accurate representation between 2011 and 2015, we need to include also geographical information that was sold at zero price. A typical example is geographical information that was given to another body of public administration free of charge. If we include such 'virtual payments' for the Czech national mapping organisation, we conclude that for each euro invested into geographical information, $€ 0.45$ are recouped. A further benefit arises with respect to activities undertaken on the basis of correct geographical information. That is, costs arising from mistakes are eliminated or reduced.

Empirical economic numbers have not been provided within Czechia and beyond since the conducted 
experiment in 2016. Nevertheless, we see indirect economic impacts between 2016 and 2021. Opening the geographic information and unifying geographic data to Creative Commons licence (CC 4.0) seem the most important drivers for both, (re-)producers and users. Four geographic datasets in a scale up to $1: 50,000$ of the civil national mapping organisation were opened between September 2016 and February 2021.

The arguments presented in this paper are intended to assist all stakeholders contributing to geographical information. Note that even though the authors have attempted to provide as detailed economic survey as possible, the transferability of results from one country to another and/or upscaling from the Czechia to continental level is hardly feasible due to the variety of financial mechanisms used in different countries and at different levels. The obtained results are being used as inputs to the upcoming Czech (national) Strategy of Geographical Information Infrastructure from the year 2021 to 2027 as a more up-to-date study has not been performed so far.

\section{Acknowledgements}

This work was supported by the Technological Agency of the Czech Republic under Grant No. TB0500MV002 titled 'Development of Analytical Draft Model for Financing Data Funds of Key Geographical Information' and by Masaryk University (Czech Republic).

The authors are grateful for the support they received from the European Commission (Directorate General Joint Research Centre and Directorate General Environment), the European Environmental Agency, the Czech Ministry of Interior, the Czech Ministry of Defence and the Armed Forces of the Czech Republic, the Czech Office for Surveying, Mapping and Cadastre, contributors to the Czech Strategy of Geographical Information Infrastructure till 2020 (GeoInfoStrategie), the experts of the INSPIRE Maintenance and Implementation Group, and all who completed the questionnaires.

\section{References}

ANZLIC (2010a): The Spatial Information Council.

Economic Assessment of Spatial Data Pricing and Access: Stage 1 Report: Principles, Issues and Alternative Models (online). Available from: https://www.crcsi.com.au /assets/Resources/ANZLIC-Economic-Study-Stage-1 -Report.pdf (Accessed 6 November 2020).

ANZLIC (2010b): The Spatial Information Council.

Economic Assessment of Spatial Data Pricing and Access: Stage 2 Report: Cost Benefit Analysis of Alternative Models (online). Available from: https://www.crcsi.com .au/assets/Resources/ANZLIC-Economic-Study-Stage-2 -Report.pdf (Accessed 6 November 2020).
Berners-Lee, T. (2006): Linked Data (online). Available from: https://www.w3.org/DesignIssues/LinkedData .html (Accessed 2 November 2020).

Castelein, T. W., Bregt, A., Pluimers, Y. (2010): The economic value of the Dutch geoinformation sector. International Journal of Spatial Data Infrastructures Research 5, 58-76, https://doi.org/10.2902/1725-0463.2010.05 .art2.

Cetl, V., Roic, M., Mastelic Ivic, S. (2008): Cost-benefit analysis of the improvement of spatial data infrastructure - Case study Croatia. Geodetski Vestnik 52(3), 475-486.

Cetl, V., Nunes de Lima, V., Tomas, R., Lutz, M., D’Eugenio, J., Nagy, A., Robbrecht, J. (2017): Summary Report on Status of implementation of the INSPIRE Directive in EU, EUR 28930 EN. (online). Available from: https://publications. jrc.ec.europa.eu/repository/bitstream/JRC109035 /jrc109035_jrc109035_jrc_inspire_eu_summaryreport _online.pdf (Accessed 23 February 2021).

Craglia, M., Pavanello, L., Smith, R. S. (2012): Are We There Yet? Assessing the Contribution of INSPIRE to EIA and SEA Studies. Journal of Environmental Assessment Policy and Management 14(1), 5-27, https://doi.org/10.1142 /S1464333212500056.

Craglia, M., Pogorzelska, K. (2020): The Economic Value of Digital Earth. In: Guo, M. et al., eds., Manual of Digital Earth. Singapore: Springer Nature, 623-643, https:// doi.org/10.1007/978-981-32-9915-3_19.

Craglia, M., Roglia, E., Tomas, R. (2014): INSPIRE Public Consultation (online). Available from: http://inspire .ec.europa.eu/reports/consultations/INSPIRE_Public _Consultation_Report_final.pdf (Accessed 6 November 2020).

Crompvoets, J., Broucker, B. (2015): Geospatial Information Broker. A New Role of National Mapping Agencies. Micro, Macro \& Mezzo Geoinformation 4, 1-10.

Crompvoets, J., de Man, E., Macharis, C. (2010): Value of Spatial Data: Networked Performance beyond Economic Rhetoric. International Journal of Spatial Data Infrastructures Research 5, 96-119, https://doi.org /10.2902/1725-0463.2010.05.art4.

Coumans, F. (2018): The Search for the Economic Value of 3D Geoinformation (online). Available from: https:// www.gim-international.com/content/article/the-search -for-the-economic-value-of-3d-geoinformation (Accessed 16 February 2021).

CZSO (2021): Inflation - Types, Definition, Tables (online). Available from: https://www.czso.cz/csu/czso/inflation _rate (Accessed 22 February 2021).

Deloitte (2018): The Socio Economic Impact of Open ELS. Final Report (online). Available from: https://openels .eu/wp-content/uploads/2019/04/Open_ELS_socio _economic_benefits_final_report_Website.pdf (Accessed 17 February 2021).

Dasgupta, A. (2013): Economic Value of Geospatial Data: The Great Enabler. (online). Available from: https:// www.geospatialworld.net/article/economic-value -of-geospatial-data-the-great-enabler/ (Accessed 16 February 2021).

DEWBERRY (2011): Final Report of the National Enhanced Elevation Assessment (revised 2012) (online). Fairfax, Va., Dewberry. Available from: http://www .dewberry.com/services/geospatial/national-enhanced -elevation-assessment (Accessed 5 November 2020). 
Di Biase, D. (2021): Nature of Geographic Information (online). Available from: https://opentextbc.ca /natureofgeographicinformation/ (Accessed 18 February 2021).

Directive 2007/2/EC of the European Parliament and of the Council of 14 March 2007 establishing an Infrastructure for Spatial Information in the European Community (INSPIRE) (online). Official Journal L 108, 0001-0014. Available from http://eur-lex.europa.eu/LexUriServ /LexUriServ.do?uri=0J:L:2007:108:0001:0014:en:PDF (Accessed 10 November 2020).

European Commission (2017): INSPIRE Monitoring and Reporting (online). Available from: http://inspire .ec.europa.eu/index.cfm/pageid/182 (Accessed 3 November 2020).

Frank, A. U. (2001): The Surveying activities at the Austrian Federal Office for Metrology and Surveying: An Economic Analysis. Vienna: Austrian Federal Ministry of Economics \& Labour.

FGDC (2010): Stages of the Geospatial Data Lifecycle pursuant to OMB Circular A-16. 2010. (online). Available from: https://www.fgdc.gov/policyandplanning/a-16 /stages-of-geospatial-data-lifecycle-a16.pdf (Accessed 5 November 2020).

Genovese, E., Roche, S., Caron, C., Feick, R. (2010): The EcoGeo Cookbook for the assessment of Geographic Information value. International Journal of Spatial Data Infrastructures Research 5, 120-144, https://doi.org /10.2902/1725-0463.2010.05.art5.

Gillespie, S. R. (2000): An Empirical Approach to Estimating GIS Benefits. Journal of the Urban and Regional Information Systems Association 12(1), 7-14.

Goodchild, M. F. (2003): The Nature and Value of Geographic Information. In: Duckham, M., Goodchild, M. F., Worboys, M. F., eds., Fundamentals of Geographic Information Science, London, UK: Taylor \& Francis, 19-31.

Halsing, D., Theissen, K., Bernknopf, R. L. (2004): A CostBenefit Analysis of the National Map, U.S. Geological Survey, Circular No. 1271. (online). Available from: https://pubs.usgs.gov/circ/2004/1271/ (Accessed 10 November 2020).

Hošková-Mayerová, S., Talhofer, V., Hofmann, A., Kubíček, P. (2013): Spatial database quality and the potential uncertainty sources. In: Proto, A., Squillante, M., Kacprzyk, J., eds., Advanced Dynamic Modeling of Economic and Social Systems. Studies in Computational Intelligence 448. Heidelberg, Germany: Springer, 127-142, https://doi.org/10.1007/978-3-642 -32903-6_10.

INSPIRE Knowledge Base (2021): Czechia - 2020: Country Fiche. (online). Available from: https://inspire.ec.europa .eu/country-fiche/czechia-2020-country-fiche (Accessed 22 February 2021).

Johnson, P. A., Sieber, R., Scassa, T., Stephens, M., Robinson, P. (2017): The Cost(s) of Geographical Open Data.
Transactions in GIS 21(3), 434-445, https://doi.org /10.1111/tgis.12283.

Klinkenberg, B. (2003): The true cost of spatial data in Canada. The Canadian Geographer 47(1), 37-49, https://doi.org/10.1111/1541-0064.02e11.

Krek, A., Frank, A. (2000): The Economic Value of Geo Information. Journal for Spatial Information and Decision Making, 13 (3), 10-12.

Kubátová, E. (2017): Aktuální stav implementace GeoInfoStrategie (online). Available from: https:// www.isss.cz/archiv/2017/download/prezentace/mvcr _kubatova.pdf (Accessed 19 February 2021).

Lü, G., Batty, M., Strobl, J., Lin, H., Zhu, A.-X., Chen, M. (2019): Reflections and speculations on the progress in Geographic Information Systems (GIS): A geographic perspective. International Journal of Geographical Information Science 33(2), 346-367, https://doi.org /10.1080/13658816.2018.1533136.

National Research Council (2004): Licensing Geographic Data and Services. Washington, DC, USA: The National Academies Press.

Obermeyer, N. J. (2008): Cost-Benefit Analysis. In: Kemp, K. K., ed. Encyclopedia of Geographic Information Science, Los Angeles, USA: SAGE Publications, 52-54, https://doi.org/10.4135/9781412953962.n27

OXERA (1999): The Economic Contribution of Ordnance Survey GB (online). Oxford Economic Research Associates, Oxford, United Kingdom. Available from: https://nsgic.memberclicks.net/assets/docs/Library /British_Ord_Survey_Economic_Paper.pdf (Accessed 4 November 2020).

Pashova, L., Bandrova, T. (2017.): A brief overview of current status of European spatial data infrastructuresrelevant developments and perspectives for Bulgaria. Geo-Spatial Information Science 20(2), 97-108, https:// doi.org/10.1080/10095020.2017.1323524

Pick, J. (2005): Costs and Benefits of GIS in Business. In: Pick, J. B., ed., Geographic Information Systems in Business. Hershey, USA: Idea Group Publishing, 56-79, https://doi.org/10.4018/978-1-59140-399-9.ch004

Řezník, T., Chudý, R., Mičietová, E. (2016): Normalized evaluation of the performance, capacity and availability of catalogue services: a pilot study based on INfrastruture for SPatial InfoRmation in Europe. International Journal of Digital Earth 9(4), 325-341, https://doi.org/10.1080/17538947.2015.1019581.

Řezník, T. (2013): Geographic information in the age of the INSPIRE Directive: Discovery, download and use for geographical information research. Geografie 118(1), 77-93, https://doi.org/10.37040/geografie 2013118010077.

Toth, K., Smits, P. (2009): Cost-Benefit Considerations in Establishing Interoperability of the Data Component of Spatial Data Infrastructures. In: Proceeding of the 24th International Cartographic Conference, 15-21 November 209 Santiago De Chile. 